\title{
Educational strategies to improve adherence to patient identification
}

Estratégias educativas para melhorar a adesão à identificação do paciente

Estrategias educativas para mejorar la adhesión a la identificación del paciente

\section{Melissa Prade Hemesath ${ }^{a}$ \\ Helena Barreto dos Santos ${ }^{a}$ \\ Ethel Maris Schroder Torelly ${ }^{a}$ \\ Amanda da Silveira Barbosa ${ }^{b}$ \\ Ana Maria Müller de Magalhães ${ }^{b}$}

D0l: $\quad$ http://dx.doi.org/10.1590/19831447.2015.04.54289 a Hospital de Clínicas de Porto Alegre (HCPA). Porto Alegre. Rio Grande do Sul. Brasil

b Universidade Federal do Rio Grande do Sul (UFRGS). Escola de Enfermagem. Porto Alegre. Rio Grande do Sul. Brasil.

\section{ABSTRACT}

Objective: The aim of this study was to analyze the impact of educational actions on the results of an adherence indicator while checking patient identification wristbands before high-risk care.

Methods: This is a descriptive and exploratory study that was conducted in a large university hospital between January 2013 and December 2014, where 6,201 patients were interviewed. Data were analyzed by descriptive statistics.

Results: The analysis and monitoring of the adherence indicator in patient identification wristbands showed a tendency to increased percentage along the study period, from 42.9\% to 57.8\% between January and April 2013,and from $81.38 \%$ to $94.37 \%$ between September and December 2014.

Conclusions: Teaching strategies based on staff awareness improved the professionals' adherence to checking patient ID wristbands. In addition, this result can contribute to strengthening the safety culture within the institution.

Keywords: Patient identification systems. Patient safety. Indicators of health service. Continuing education.

\section{RESUMO}

Objetivo: analisar o impacto de ações educativas nos resultados do indicador de adesão à verificação da pulseira de identificação de pacientes, antes da realização de cuidados de maior risco.

Métodos: estudo descritivo e exploratório, conduzido em hospital universitário de grande porte, entre janeiro de 2013 e dezembro de 2014, com 6.201 pacientes entrevistados. Os dados foram analisados por meio de estatística descritiva.

Resultados: a análise e o acompanhamento do indicador de adesão ao uso da pulseira de identificação do paciente demonstraram uma tendência de aumento do percentual, atingindo, ao longo do período estudado, de 42,9\% a 57,8\%, entre janeiro e abril de 2013, e de $81,38 \%$ a 94,37\%, entre setembro e dezembro de 2014.

Conclusões: as estratégias educativas, ancoradas na sensibilização da equipe, otimizaram a adesão dos profissionais à verificação da identificação do paciente, o que contribui para o fortalecimento da cultura de seguranç̧a na instituiç̧ão.

Palavras-chave: Sistemas de identificação de pacientes. Segurança do paciente. Indicadores de serviços. Educação continuada.

\section{RESUMEN}

Objetivo: analizar el impacto de las acciones educativas en los resultados del indicador de adhesión a la verificación de la pulsera de identificación de los pacientes hospitalizados, previo a la atención más arriesgada.

Métodos: estudio descriptivo y exploratorio, realizado en gran hospital universitario, entre enero de 2013 y diciembre de 2014, con 6.201 pacientes entrevistados. Los datos se analizaron mediante estadística descriptiva.

Resultados: el análisis y el acompañamiento del indicador de adhesión al uso de la pulsera de identificación del paciente ha demostrado una tendencia de aumento del porcentual, alcanzando a lo largo del periodo estudiado, de 42,9\% a 57,8\% entre enero y abril de 2013 para 81,38\% a 94,37\% entre septiembre y diciembre de 2014.

Conclusiones: las estrategias educativas, ancladas en la conciencia de equipo, han optimizado la adherencia de los profesionales para verificar la identificación del paciente, lo que ayuda a fortalecer la cultura de seguridad en la institución.

Palabras clave: Sistemas de identificación de pacientes. Seguridad del paciente. Indicadores de servicios. Educación continuada. 


\section{DINTRODUCTION}

The concern about quality and safety in health services in the area of health management has increased. The search for excellence in medical service and the need to offer services with minimized risk to patients have become a great challenge to health organizations worldwide.

Initiatives of the World Health Organization (WHO) leading to the launch of the World Alliance for Patient Safety in 2004 have intensified the implementation, by health organizations and institutes, of methodologies to systematically evaluate patient safety risks in health services, with the aim to increase service quality ${ }^{(1)}$. For this reason, indicators have been implemented to monitor quality and evaluate the results of services offered to patients in hospital organizations ${ }^{(2)}$.

Studies published by the Institute of Medicine ${ }^{(3)}$ and the $\mathrm{WHO}^{(1)}$ have cautioned the academic community and society as a whole about aspects that involve risks resulting from errors or faults that may lead to damage or even death in patients in current health systems. In 2005, the WHO, in a partnership with the Joint Commission International $(\mathrm{JCI})^{(4)}$, created the Collaborating Centre for Patient Safety Solutions, to disseminate the following six International Patient Safety Goals: 1. Identify patients correctly; 2. Improve effective communication (regarding prescriptions and results of diagnostic tests); 3 . Improve the safety of high-alert medications; 4. Ensure correct-site, correct-procedure, correct-patient surgery; 5 . Reduce the risk of health care-associated infections; 6 . Reduce the risk of patient harm resulting from falls.

These goals have been implemented and supervised worldwide in hospitals in an international accreditation process $^{(5)}$.

Then, correct patient identification has been adopted as one of the goals to ensure patient safety worldwide and, in 2013, it became part of the National Program for Patient Safety (PNSP, Programa Nacional de Segurança do Paciente) in Brazil, which promotes and supports the implementation of patient safety initiatives in different areas of health attention, organization, and services ${ }^{(6)}$.

The consequences of possible faults in health systems have a negative impact on patients and their families, on health organizations, and on society. Studies have demonstrated that the occurrence of adverse events in services to hospitalized patients may lead to complications in patient recovery, increased infection rates, and hospitalization time ${ }^{(7-8)}$. The fact that about one out of 10 admissions results in at least one adverse event is alarming, especially when we consider that half of these incidents are preventable, according to studies conducted in American hospitals ${ }^{(9-10)}$.
In Brazil, a study conducted in three university hospitals showed an incidence of adverse events of $7.6 \%$, of which $66.7 \%$ were considered preventable ${ }^{(11)}$. These findings, combined with initiatives such as the Brazilian Network of Nursing and Patient Safety (REBRAENSP, Rede Brasileira de Enfermagem e Segurança do Paciente), created in 2008 in a partnership with the Pan-American Health Organization (PAHO), further strengthened the intention to disseminate a safety culture among institutes, professionals, and families of patients in Brazil ${ }^{(12)}$.

According to the National Patient Safety Agency (NPSA) (13), between February 2006 and January 2007, 24,382 reports of situations incompatible with patient care were received, and it was estimated that approximately 2,900 of these incidents were related to the use of identification wristbands, such as an absent wristband or incorrect information on the wristband. The NPSA warns that these situations may increase the risk of incorrect patient identification, and inadequate treatment may be provided. In addition, it points out that the standardization of identification wristbands, information on wristbands, and processes used in data verification in critical moments are essential for improved patient safety.

Considering the facts above, it is extremely important to adopt indicators and monitoring of processes to reduce the impact of errors in patients in health systems. The studied hospital, concerned about monitoring and improving this process, developed and implemented, in January 2013, an indicator that shows the adherence of health professionals to patient ID verification in critical moments, as recommended by commonly known protocols.

Aiming to evaluate whether educational actions effectively make professionals aware of safe practices, the following question was formulated: Can educational actions improve the results of adherence to patient ID verification by health professionals?

The objective of this study is to analyze educational actions as a result of the indicator "adherence rate of health professionals in patient ID wristband verification," discussing the adherence of professionals to the process before they provide high-risk care.

\section{口 METHODOLOGY}

This is a descriptive exploratory study of a quantitative approach conducted in a university hospital in the city of Porto Alegre. This university hospital has 843 beds and offers adult and pediatric admission. Throughout the whole year of 2012, the process of patient identification was discussed and redesigned. Before that, the hospital had already adopted a practice to identify its patients through 
wristbands, but the ID information was manually written and not standardized. In some situations, the professionals added the patient bed; in others they would not write the patient's full name or would forget to add the patient ID number. The ID verification routine was not uniformly practiced in the institute.

Based on the guidelines from the main entities that have addressed questions of health service quality and patient safety ${ }^{(1,5,13)}$, which recommend the adoption of at least two patient ID elements, this hospital discussed and revised its patient identification process, adopting the patient's full name and patient ID number as identification elements. The institute assumed the mandatory verification of these indicators by health professionals before providing high-risk care (such as administration of medication and blood and blood components, before collecting blood samples and other samples for tests, and before invasive procedures and other treatments) starting in January 2013.

Since then, the hospital has used a new indicator of service quality and patient safety to evaluate the adherence of health professionals to this new process. This indicator attempts to measure the compliance of patient ID verification on the wristband before care provision. This new process was measured through interviews with patients from 17 admission units of the hospital that questioned the perceptions of the patient, family member, or accompanying person of wristband verification by health professionals before the provision of high-risk care, such as administration of medication, blood sample collection, diet delivery, or invasive procedures. The number of answers "yes" indicated the percentage of health professionals' adherence to patient ID verification routine.

Data about the indicator were collected through daily interviews with 18 patients hospitalized in the admission units for adult and pediatric patients. The patients were randomly allocated for the interview, and patients from two admission units were interviewed. In the pediatric units, the interview was conducted with the pediatric patients' parents or accompanying persons.

The sample was calculated considering 40\% adherence to ID verification, which was the prevalence observed in the second half of 2012 before implementation of the indicator; $5 \%$ error was considered valid. For a significant sample, 306 patients a month, or 18 patients a day, were to be interviewed.

Nine patients were randomly chosen from two units daily, following a fixed schedule, so that every unit was visited the same number of times a month. The selection of patients for the interview was as follows: the total number of eligible patients was divided by nine and the whole number of the result was chosen as the first patient. This was the first patient to be interviewed; the second was the ninth patient, considering the increasing number of beds with eligible patients in the unit, and returning to the first bed of the unit when the numbering ended, and so on, until the ninth patient was reached. If any of the selected patients were not in the bed or were unable to answer, or had no accompanying person to speak for them, the next patient was selected, but the selection followed the initial numerical order.

The interviewed patients (or family members/accompanying the patient) had been hospitalized for over 24 hours. The exclusion criteria were: patients hospitalized for less than 24 hours, patients in isolated areas or with contact restriction, patients unable to communicate or without a family member/accompanying them at the interview moment.

In the interview, the investigator informed patients or their family members of the purpose of the questionnaire and ensured confidentiality regarding the information provided, verbally asking for the consent of patients or family members/accompanying persons to participate in the interview.

At the end of the interview, the investigator informed the patient that wristband verification is a safety action to ensure that the patient receives the correct treatment. This information was provided to promote patient collaboration with this safety action, which is also recommended by the Joint Commission International ${ }^{(4-5)}$.

Data were collected from January 2013 to December 2014, stored as a Microsoft Excel for Windows ${ }^{\oplus}$ document, and transferred to a computer system: the Strategic and Operational Management-Strategic Advisor, in Performance Manager module, which presents all of the hospital's strategic and operational indicators. Data were stored in the indicator "Adherence Rate of Professionals to Patient ID Wristband Verification."The sample included 6,201 subjects, consisting of patients, admitted patients, or their family members/accompanying persons.

Result analysis was conducted with descriptive statistics, which provided indicator percentages in the different periods of data collection for the hospital in general. During the indicator monitoring, educational strategies and managerial actions were implemented to improve the results.

The first strategy was an institutional educational campaign, with the production of a video, signs, and brochures with the six International Patient Safety Goals proposed by the Joint Commission International, which took place in April 2013.

The second action was the development of a distance course that included the video from the first action show- 
ing all processes that involve the six goals, and procedures to be observed by health professionals to achieve such goals, and optimize patient safety and process quality. This action took place in October 2013.

The third strategy was the development and provision of a distance course specific to the identification process, named "Correct Patient Identification as a Safety Measure." This course was offered to the target audience of the hospital starting in May 2014, and it was incorporated into the institutional training matrix. It is a mandatory training for all professionals from nursing, nutrition, physical therapy, sample collectors, and technical professionals in the test areas, which are the professional categories directly involved in the provision of care that include prior patient identification, such as administration of medication, blood collection, and diets, and procedures before conducting sample collection and tests.

This distance course used cases published in the media and available on the Internet. Five cases were selected, including corpses switched in a hospital morgue; patient medications switched in the emergency room; babies switched in a maternity ward; test results switched due to similar patient names; patients switched during blood transfusion. These media cases were pooled and edited into a video format, using the software Flash Player for animation, and removing the identification of the institutes to prevent exposure, although these are public cases.

In addition to these media cases, four other real or invented descriptive cases about errors from identification faults were presented. After that, the cases were discussed, and the professionals were asked whether, in their opinion, similar cases could happen in their hospital. After this phase, a multiple-answer question was included about what main adjustment should have been implemented to prevent those errors.

From halfway through until the end of the course, the theoretical content about patient the identification process was presented, which involved patient ID verification at the moment of admission, ID confirmation and placement of a wristband with the identification elements, and verification of identification elements, highlighting that such verification is mandatory before providing high-risk care. A test ensured the course conclusion and approval of professionals, with three questions about the theoretical content presented in the course.

This study was approved by the Research Ethics Committee of the institute, under protocol number 14-0478, respecting the guidelines from Resolution 466/2012 of the National Health Council of the Ministry of Health ${ }^{(14)}$.

\section{RESULTS}

Figure 1 shows the institutional indicator performance during the study period, with indications of when the three educational actions started.

The results from the indicator show that, in the beginning of this new routine, the adherence of professionals was extremely low. In January 2013, when the routine was implemented, the adherence rate was $42.90 \%$. In the following months, it increased to around 50\%.

After implementation of the first educational action, started in April 2013, an improved adherence rate was obtained. In May, the adherence rate was $72.95 \%$, reaching a peak rate of $81 \%$ in June; the last result was obtained in 2013, which exceeded the target of $80 \%$.

In August, a reduced rate of about $65 \%$ was observed. In November 2013, after the second educational action, the adherence rate to the patient identification process was $76 \%$.

In the first quarter of 2014, the rate remained $65 \%$ on average. In May 2014, after the third educational strategy, the results of the indicator improved, exceeding the target of $80 \%$. In 10 months, the distance course reached 4,719 people in total out of total audience of 6,727 (70.15\%), considering the mandatory and non-mandatory audience. Considering the nursing professionals only (nurses, nursing technicians, and assistants), totaling 1,851 professionals, 1,675 (90.49\%) nursing professionals attended the distance course.

In May and June, the adherence rate of the professionals to the process remained lower than the target of 80\%: $70.11 \%$ and $74.42 \%$, respectively. Gradually, as the professionals ended the course, the results increased and exceeded the target, with a peak rate of $94.37 \%$ in September 2014. After the course, the adherence of professionals to the process remains above the target.

\section{DISCUSSION}

The guidelines for a proper patient identification implementation recommend that the institutes adopt uniform methods to identify their patients, such as ID wristbands, with at least two identification elements. In addition, the wristband use should be disseminated and wristband verification should be ensured before high-risk procedures, especially before the administration of medication, blood and blood components, sample collection, diagnostic tests, and surgical procedures ${ }^{(1,4,6)}$.

In addition to the implementation of new routines and protocols to increase patient safety, it is important to 


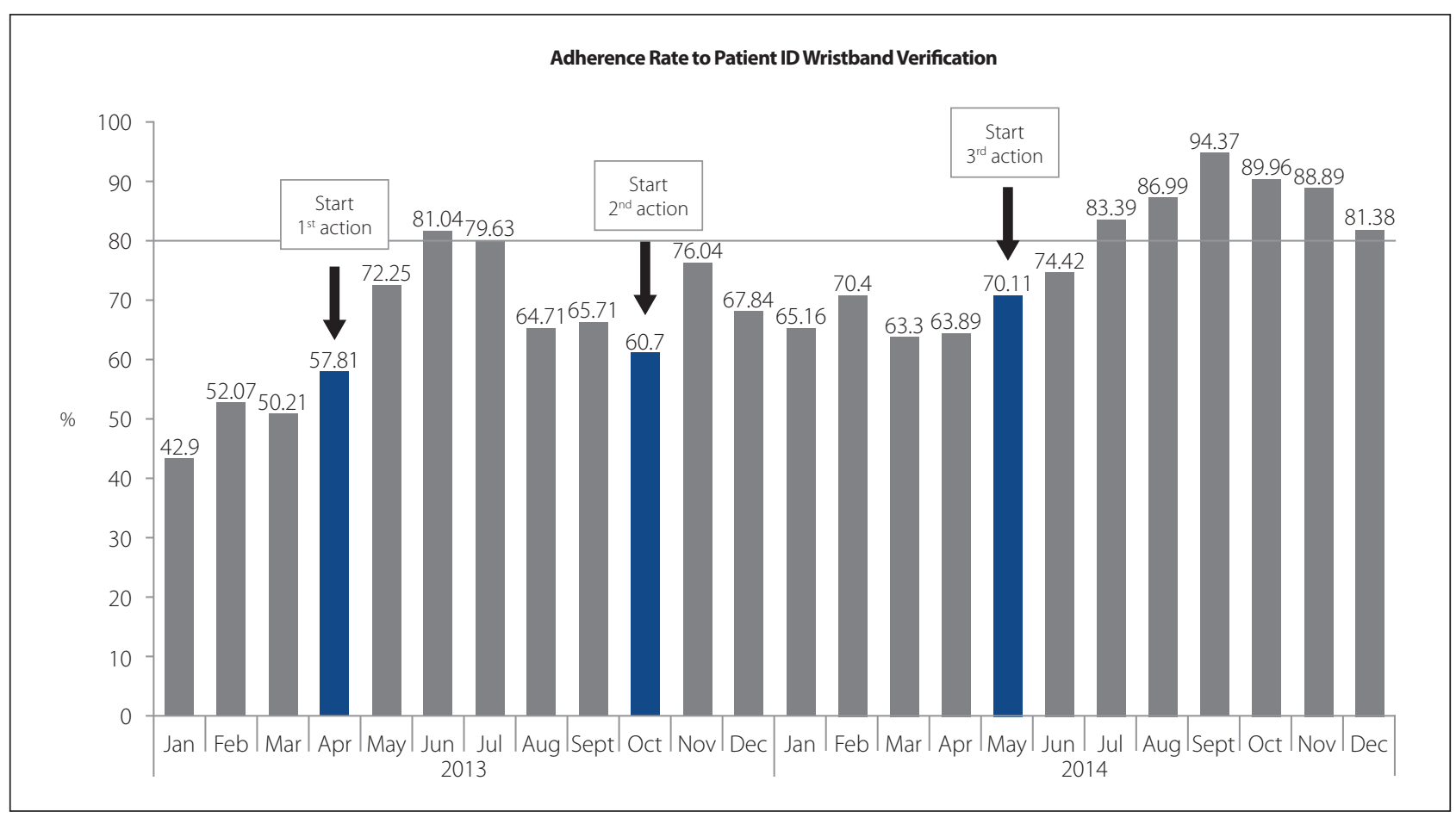

Figure 1 - Results of indicator: "Adherence Rate to Patient ID Wristband Verification" in 2013 and 2014, Porto Alegre, RS Source: Study data.

develop educational strategies and managerial monitoring actions to support safe and evidence-based practices.

In this sense, the involvement of professionals and the commitment of managers are essential, considering that uncritical use of scientific knowledge or a partial implementation of protocols in health institutes without the involvement of professionals does not allow the achievement of the desired level of safety and quality, and it may cause risks to the health of both patients and professionals ${ }^{(15)}$.

The analysis and monitoring of the patient identification adherence indicator showed a tendency of increasing percentage during the study period, from $42.9 \%$ to $57.8 \%$ between January and April 2013, to $81.38 \%$ and then to $94.37 \%$ between September and December 2014. This result was reached with efforts to strengthen a safety culture in the hospital, which led to revision of processes and adoption of protocols to prevent adverse events, including faulty patient identification, which may cause errors in the administration of medication and diets, as well as incorrect tests and surgical or hemotherapic procedures, among others.

These findings are confirmed by studies that emphasize the importance of the adoption of health-team awareness and education strategies, aiming to imple- ment new practices in a collaborative and constructive manner, highlighting that the participation of nursing professionals is essential to reduce faulty patient identification and consolidate quality services with safety ${ }^{(16-17)}$.

Educational strategies are central mechanisms for the dissemination and commitment to a safety culture, and for the introduction of new practices and procedures that may become barriers to process faults ${ }^{(18)}$. In the last distance course provided in the strategy, specifically addressing patient identification, the introduction started with problems that may result from faulty patient identification, warning professionals that a simple verification of the patient identification elements on the wristband can prevent a number of adverse events.

Using real examples and situations of routine practice of health professionals and students is considered an essential educational principle to improve safety results of patients. Using real facts helps ensure meaning and favors learning to improve health care environments ${ }^{(19)}$.

It should be noted that, despite intensive measures for patient identification, a British study indicates the use of ID wristbands is widely recommended, but it has not been deeply analyzed; the potential of wristbands has not been fully explored in the prevention of adverse 
events to patients, but such use in practice still has to be further investigated ${ }^{(20)}$.

\section{CONCLUSIONS}

A revision of processes and the implementation of a new protocol, based on educational strategies and managerial actions, showed gradual improvement in the adherence of health professionals to patient identification wristband verification before care provision. Such improvement in adherence was observed exactly when educational and routine reinforcement campaigns were conducted, including a distance course that emphasized the fact that adherence was a question of safety to patients and health professionals providing care.

Educational measures as a way to reinforce the routine of patient identification are essential to consolidate practices, optimizing patient safety in health institutes. Regarding the relevance of the results obtained in this study, they should be interpreted considering the limitation of a descriptive and cross-sectional design in a single hospital, not allowing to generalization of the findings.

Complementary studies to monitor this and other indicators may indicate weaknesses and opportunities for improvement in patient safety.

\section{REFERENCES}

1. World Health Organization (CH), World Alliance for Patient Safety. Summary of the evidence on patient safety: implications for research. Geneva; 2008.

2. Moura GMSS, Juchem BC, Falk MLR, Magalhães AMM, Suzuki LM. Construção e implantação de dois indicadores de qualidade assistencial de enfermagem. Rev Gaucha Enferm. 2009;30(1):136-40.

3. Kohn LT, Corrigan JM, Donaldson MS, editors. To err is human: building a safer health system [Internet]. Washington, DC: National Academy Press; 2000 [cited 2014 Jun 9]. Available from: http://www.nap.edu/openbook.php?record_ id $=9728 \&$ page $=R 3$

4. Joint Commission International (US). International patient safety goals created. Jt Comm Perspect. 2006;26(2):8.

5. Wachter RM. Patient safety at ten: unmistakable progress, troubling gaps. Health Aff. 2010;29(1):165-73.

6. Ministeŕrio da Saúde (BR). Portaria no 529 de 10 de Abril de 2013. Institui o Programa Nacional de Segurança do Paciente (PNSP). [Internet]. Diário Oficial da União [da] República Federativa do Brasil. 2013 abr. 02;150(62 Seção 1):43-4.

\section{Author's address:}

Melissa Prade Hemesath

Rua Ramiro Barcelos, 2350, Largo Eduardo Z. Faraco

90035-903 Porto Alegre - RS

E-mail: mhemesath@hcpa.edu.br
7. Needleman J, Buerhaus P, Pankratz VS, Leibson CL, Stevens S, Harris M. Nurse staffing and inpatient hospital mortality. New Engl J Med. 2011;364(11):103745.

8. Curran CR, Totten MK. Governing for improved quality and patient safety. Nurs Econ. 2011;29(1):38-41.

9. Wachter RM. Compreendendo a segurança do paciente. Porto Alegre: Artmed; 2010.

10. Wilson RMCL, Weyden MBVD. The safety of Australian healthcare: 10 years after QAHCS.Med J Aust [Internet]. 2005 [cited 2013 Mar 20];182(6):260-1. Available from:http://www.mja.com.au/public/issues/182_06_210305/ wil10087_fm.html

11. Mendes ACG, Araújo Jr. JLCA, Furtado BMAS, Duarte PO, Santiago RF, Costa TR. Avaliação da satisfação dos usuários com a qualidade do atendimento nas grandes emergências de Recife, Pernambuco, Brasil. Rev Bras Saúde Mater Infant. 2009;9(2):157-65.

12. Batalha EMSS. A cultura de segurança do paciente na percepção de profissionais de enfermagem de um hospital de ensino [dissertação]. São Paulo: Universidade de São Paulo; 2012.

13. Norris B, Ranger C. Standardising wristbands improves patient safety: guidance on implementing the safer practice notice (SPN 24, July 2007) and the related information stands approved by the Information Standards Board for Health and Social Care in March 2009 [Internet].London: National Patient Safety Agency; 2009 [cited 2014 Dec 10]. Available from:http://www.npsa.nhs.uk/EasysiteWeb/getresource.axd?Asset|D=57989\&type=Full\&servicetype=Attachment

14. Ministério da Saúde (BR), Conselho Nacional de Saúde. Resolução no 466, de 12 de dezembro de 2012. Diretrizes e normas regulamentadoras de pesquisas envolvendo seres humanos. Diário Oficial da União [da] República Federativa do Brasil. 2013 jun 13;150(112 Seção 1):59-62.

15. D'Innocenzo M, Feldman LB, Fazenda NRR, Helito RAB, Ruthes RM. Indicadores, auditorias, certificaçoes: ferramentas de qualidade para gestão em saúde. São Paulo: Martinari; 2010.

16. Hoffmeister LV, Moura GMSS. Use of identification wristbands among patients receiving inpatient treatment in a teaching hospital. Rev Latino-Americana Enfermagem. 2015;23(1):36-43

17. Neves $L A C$, Melgaço RMT. A identificação do paciente como indicador de qualidade. Rev Eletr Acred [Internet]. 2011 [acesso em: 2015 jun 08]; 1(1):88-100. Disponível em: http://www.cbacred.org.br/ojs/index.php/Acred01/article/ view/17

18. Lathem T, Malomboza O, Nyirenda L, Ashford P, Emmanuel J, M'baya B, et al. Quality in practice: implementation of hospital guidelines for patient identification in Malawi. Int J Qual Health Care. 2012;24(6):626-33.

19. World Health Organization (CH). Patient safety curriculum guide:multi-professional edition. Geneva; 2011

20. Smith AF, Casey K. Wilson J, Fischbacher-Smith D. Wristbands as aids to reduce misidentification: an ethnographically guided task analysis. Int I Qual Health Care. 2011;23(5):590-9. 